\title{
Smoking Relapse and Type 2 Diabetes Mellitus-Related Emergency Department Visits Among Senior Patients with Diabetes
}

\author{
Yu-Hsiang Kao, $\mathrm{PhD}^{1}$; Michael D. Celestin Jr, MA ${ }^{1}$; Carl D. Walker, $\mathrm{MD}^{2}$; Qingzhao Yu, $\mathrm{PhD}^{3}$; \\ John Couk, MD²; Sarah Moody-Thomas, $\mathrm{PhD}^{1}$; Huijie Zhang, $\mathrm{MD}^{4}$; Tung-Sung Tseng, $\mathrm{DrPH}^{1}$
}

Accessible Version: www.cdc.gov/pcd/issues/2019/19_0027.htm

Suggested citation for this article: Kao YH, Celestin MD Jr, Walker CD, Yu Q, Couk J, Moody-Thomas S, et al. Smoking Relapse and Type 2 Diabetes Mellitus-Related Emergency Department Visits Among Senior Patients with Diabetes. Prev Chronic Dis 2019;16:190027. DOI: https://doi.org/10.5888/ pcd16.190027.

\section{PEER REVIEWED}

\section{Summary}

What is already known on this topic?

People with diabetes who smoke are more likely to have serious health problems compared with their nonsmoking counterparts. The American Diabetes Association guidelines suggest that patients with diabetes quit smoking to improve diabetes management.

What is added by this report?

We identified the patient's smoking status in the past 30 days and in the past year by using electronic health records. Among older patients with diabetes, continuing and relapsed smokers with diabetes had a higher risk for type 2 diabetes mellitus-related emergency department (ED) visits.

\section{What are the implications for public health practice?}

The results of our study suggest that older smokers with diabetes should remain abstinent from smoking to decrease type 2 diabetes-related ED visits.

\section{Abstract}

\section{Introduction}

Quitting smoking has been proven to benefit smokers with diabetes. However, among older patients with diabetes, the evidence regarding an association between smoking status and the risk of type 2 diabetes mellitus-related emergency department (ED) visits has not been well investigated.

\section{Methods}

A retrospective cohort study was performed by using the Louisiana State University Health Care Services Division electronic health records from 2009 to 2011. Patients aged 65 years or older with type 2 diabetes and smoking status recorded at least twice in 2010 were selected. Selected patients with diabetes were classified into nonsmokers, former smokers, continuing smokers, and relapsed smokers. Cox proportional hazards regression models were used to estimate the adjusted hazard ratio (aHR) of 1-year type 2 diabetes-related ED visits for each group compared with nonsmokers.

\section{Results}

There were $174(8.2 \%)$ continuing smokers and 77 (3.6\%) relapsed smokers in 2,114 patients with diabetes who were studied. Rates of type 2 diabetes-related ED visits were highest in relapsed smokers (28.6\%). Compared with nonsmokers, relapsed smokers had a significantly higher risk of type 2 diabetes-related ED visits $(\mathrm{aHR}=1.62 ; 95 \%$ confidence interval $[\mathrm{CI}], 1.04-2.50)$. After stratifying by sex, a significantly increased risk of type 2 diabetes-related ED visits was shown only in male relapsed smokers $(\mathrm{aHR}=2.05 ; 95 \% \mathrm{CI}, 1.13-3.71)$ and female continuing smokers $(\mathrm{aHR}=1.65 ; 95 \% \mathrm{CI}, 1.10-2.47)$ compared with nonsmokers.

\section{Conclusion}

Older men with diabetes who were relapsed smokers had a higher risk of type 2 diabetes-related ED visits. Future research and clinical practice should focus on these patients and create more effective interventions for smoking cessation and diabetes management.

\section{Introduction}

Type 2 diabetes mellitus, a highly prevalent disease, is a major cause of illness and death worldwide (1). People with diabetes are more likely to use health care services, including inpatient, outpa- 
tient, and emergency department (ED), than those without diabetes (2). According to the 2017 National Diabetes Statistics Report, 30.3 million Americans had diabetes, of whom 12 million were aged 65 years or older (3). Older patients with diabetes have higher mortality (4) and ED use than younger patients with diabetes (5) and have approximately double the health care expenditures compared with their younger counterparts (6). Moreover, older patients with diabetes have a much higher rate of diabetesrelated ED visits than younger patients with diabetes (aged 18-44 or 45-64 years) (5). Hence, research on older patients with diabetes is needed now because of the aging society.

Smoking is a risk factor for developing diabetes (7). People with diabetes who smoke are more likely to have serious health problems compared with their nonsmoking counterparts. Smokers with diabetes have a higher risk of developing serious complications (7), worse metabolic control (8), and periodontal inflammatory conditions (9), which likely lead to a lower quality of life and increased mortality (10). Benefits of smoking cessation have been demonstrated in smokers with diabetes, such as better glycemic control if they quit smoking (11). Therefore, the American Diabetes Association guidelines strongly suggest that patients with diabetes quit smoking to improve diabetes management, even if they are older than 65 (12). However, the association between smoking and diabetes-related ED visits for older patients with diabetes is not well understood. Therefore, the primary objective for this study was to investigate the association between smoking and the likelihood of diabetes-related ED visits among older patients with diabetes.

\section{Methods}

This study applied a retrospective study design by using the Louisiana State University (LSU) Health Care Services Division (HCSD) data sets from 2009 to 2011. The LSU HCSD, which operates 7 public hospitals and clinics in Louisiana, is the largest provider of health care to Louisiana's uninsured and low-income citizens (13). Approximately $60 \%$ of adult patients in the LSU HCSD outpatient clinic population are uninsured; in addition, $45 \%$ of all adult clinic patients are eligible for free care under Louisiana law. Free care eligibility is determined by household income and household size, with eligibility available to patients from households falling below $200 \%$ of the federal poverty guidelines (13). The electronic health record (EHR) (14) is a tool that has demonstrated great efficiency as part of an integrated approach to not only support caregivers' decisions but also improve patients' outcomes and can be used to assist with tobacco use intervention $(13,15)$. The benefits of the EHR for providing recommendations for clinical action steps on tobacco use cessation have been established (16). For example, documentation of tobacco use status and referral to cessation counseling have been shown to increase after using the EHR to record and treat patient tobacco use at medical visits (17). Our study protocol was reviewed and approved by the Institutional Review Board of LSU HCSD—New Orleans.

\section{Study subjects}

A total of 130,281 patients who had at least 1 smoking status record (has or has not smoked in past 30 days) in 2010 in the LSU HCSD database were selected. The index date was set as the latest date for patients who had a record that demonstrated smoking status. Patients who did not have at least 2 ambulatory visits or 1 inpatient admission for type 2 diabetes mellitus (18) as a major diagnosis (International Classification of Diseases, Ninth Revision, Clinical Modification [ICD-9-CM], codes 250.x 0 and 250.x2) (19) in the preceding year of the index date were excluded $(\mathrm{n}=118,694)$. According to Centers for Medicare and Medicaid Services (CMS) Chronic Conditions Data Warehouse condition algorithms, qualified patients with diabetes had had at least 2 outpatient visits or at least 1 inpatient visit with a diabetes diagnosis (18). Additionally, when considering patients with 2 outpatient visits with diabetes, a prior study stated it may be helpful to exclude people who might be coded while they are suspected of having diabetes but were not formally diagnosed or were miscoded (19). Furthermore, patients aged less than 65 years at the index date $(n=9,114)$ were excluded. Lastly, 359 patients were excluded because the duration between the first and last record of smoking status was less than 90 days. In total, 2,114 patients were included (Figure 1).

\footnotetext{
The opinions expressed by authors contributing to this journal do not necessarily reflect the opinions of the U.S. Department of Health and Human Services, the Public Health Service, the Centers for Disease Control and Prevention, or the authors' affiliated institutions.
} 


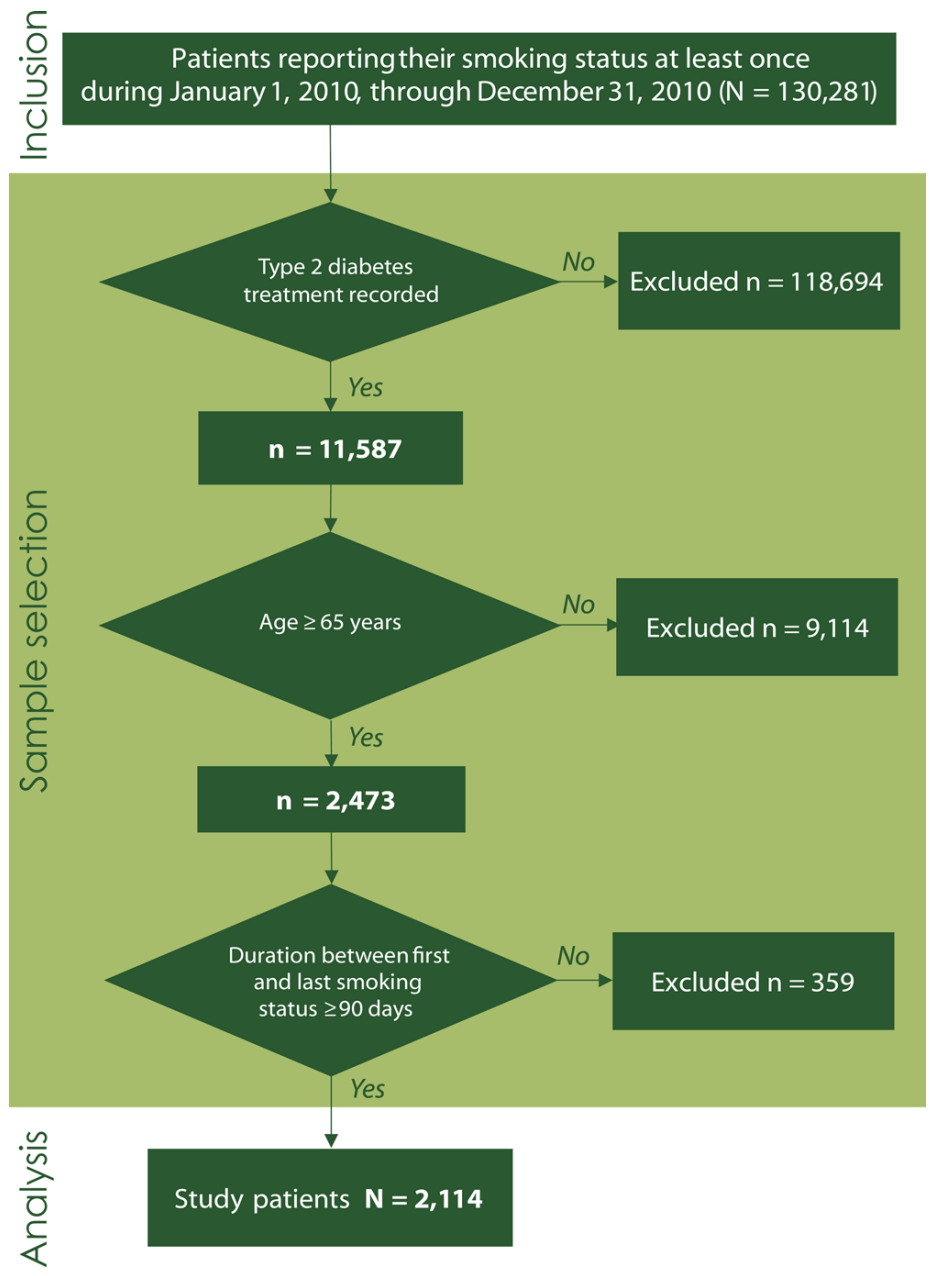

Figure 1. Sample selection for study of type 2 diabetes mellitus and smoking, Louisiana State University Health Care Services Division, 2009-2011.

\section{Assessment of smoking status}

Based on the patient's smoking status in the past 30 days and in the past year, smoking status was classified into 4 types: nonsmoker, former smoker, continuing smoker, and relapsed smoker (Figure 2). Nonsmokers were patients who did not have a record of smoking at the initial time point (past 30 days and past year), last time point (past 30 days), and in the duration between the 2 time points $(n=1,777)$. Continuing smokers were patients who reported that they had smoked at the initial time point (past 30 days and past year), last time point (past 30 days), and all records in the duration between the initial and last time point $(\mathrm{n}=$ 174). Former smokers $(n=86)$ were patients with 1 of the following 3 conditions: 1) reported that they had smoked at the initial time point (past 30 days or past year), had not smoked at the last time point (past 30 days), and had at least 1 change from smoking to not smoking in the duration between the initial and last time point $(\mathrm{n}=49) ; 2)$ reported that they had not smoked at the initial time point (past 30 days or past 1 year), had not smoked at the last time point (past 30 days), and had at least 1 change from not smoking to smoking in the duration between the initial and last time point $(\mathrm{n}=33)$; or 3 ) reported that they had not smoked at the initial time point (past 30 days) but smoked in the past year, had not smoked at the last time point (past 30 days), and had no changes in the duration between the initial and last time point ( $\mathrm{n}=$ $4)$. Relapsed smokers $(n=77)$ were patients with 1 of the following 3 conditions: 1 ) reported that they had not smoked at the initial time point (past 30 days or past 1 year), had smoked at the last time point (past 30 days), and had at least 1 change from not smoking to smoking in the duration between the initial and last time point $(n=43) ; 2)$ reported that they had not smoked at the initial time point (past 30 days or past year), had smoked at the last time point (past 30 days), and had at least 1 change from smoking to not smoking in the duration between the initial and last time point $(n=29)$; or 3 ) reported that they had not smoked at the initial time point (past 30 days) but smoked in the past year, had smoked at the last time point (past 30 days), and had at least 1 change from not smoking to smoking in the duration between the initial and last time point $(\mathrm{n}=5)$.

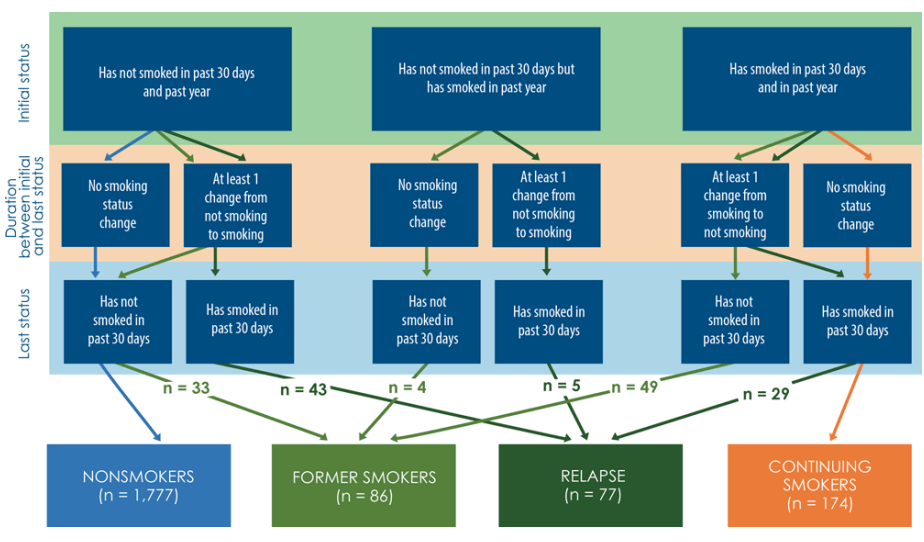

Figure 2. Patterns of identifying smoking status among patients with type 2 diabetes mellitus, Louisiana State University Health Care Services Division, 2009-2011. There was no significant difference in days of duration between initial and last status across 4 smoking status groups $(P=.667)$.

\section{Emergency department use for diabetes}

The outcome in our study concerned diabetes-related ED visits which were identified by principal ICD-9-CM diagnostic codes (250.00, 250.10, 250.20, 250.30, 250.40, 250.50, 250.60, 250.70, $250.80,250.90,250.02,250.12,250.22,250.32,250.42,250.52$, 250.62, 250.72, 250.82, and 250.92) (19). An ED visit was defined as an event that occurred during the outcome period. The follow- 
up duration was defined as the number of days from the study index date to the date of the end of a diabetes-related ED visit. If a patient had no ED visit for diabetes, then that patient was removed at the end of the 1-year follow-up period.

\section{Covariables}

Numerous control variables were considered in this study. Patient characteristics used in this study were age, sex, race (20), and insurance type (commercial, free care, Medicare, Medicaid, and selfpay) (21). Although patient educational level or household income may have affected health care outcomes (20), the HCSD claims data set did not provide this information. Therefore, insurance type was used as a proxy for socioeconomic status. In addition, health status and comorbidity may affect ED use (20); therefore, the Charlson comorbidity index (CCI) (21), number of ambulatory visits and hospitalizations for diabetes (21), congestive heart failure (CHF), peripheral vascular disease (PVD), cerebrovascular disease (CVD), and chronic pulmonary disease (CPD) $(5,22)$ were included if they occurred during the year before the index date. CCI was calculated for each patient according to outpatient or inpatient care by using the Quan adaptation of the Elixhauser comorbidities (22).

\section{Statistical analysis}

The association of patient characteristics with smoking status was examined by using a $\chi^{2}$ test for categorical variables and a 1-way analysis of variance for continuous variables. Cox proportional hazards regression models were used to examine the association between smoking status and the risk of diabetes-related ED visit in older patients with diabetes. In the adjusted model, we calculated the adjusted hazard ratio (aHR) after adjusting for sex, age, race, insurance type, number of ambulatory visits for diabetes, hospitalization for diabetes, CCI, CHF, PVD, CVD, and CPD. No variable had multicollinearity in the adjusted model. Furthermore, we stratified by sex to investigate the association between smoking status and diabetes-related ED visits that may be attributable to sex differences in smoking cessation (23). In addition, the proportional hazard assumption was tested for all models (24). All analyses were performed by using SAS version 9.4 (SAS Institute Inc). All tests were 2 -sided, and a $P$ value of less than .05 was defined as significant.

\section{Results}

Across the entire sample $(\mathrm{N}=2,114)$, the mean age was 71.0 years (standard deviation [SD], 5.6), and $64.2 \%$ of the patients were women (Table 1). There were $1,777(84.1 \%)$ patients identified as nonsmokers, $86(4.1 \%)$ as former smokers, $174(8.2 \%)$ as continuing smokers, and $77(3.6 \%)$ as relapsed smokers. Almost half
$(48.5 \%)$ of the patients were white, and $73.9 \%$ of the patients had Medicare. Regarding medical conditions, $32.8 \%$ of the patients had had 5 or more outpatient visits for diabetes; patients had histories of CHF (8.5\%), PVD (2.5\%), CVD (1.8\%), and CPD $(6.7 \%)$. The overall incidence of diabetes-related ED visits was $19.6 \%$, and the rate among patients who were relapsed smokers and continuing smokers were $28.6 \%$ and $22.4 \%$, respectively (Table 1).

After adjustment, relapsed smokers had a significantly higher risk of diabetes-related ED visits (aHR, 1.62; 95\% confidence interval [CI], 1.04-2.50) (Table 2). Despite there being no significant difference for continuing smokers compared with nonsmokers, results showed an increased risk of diabetes-related ED visits for continuing smokers, for both crude (cHR, 1.19; 95\% CI, 0.85-1.65) and adjusted (aHR, 1.19; 95\% CI, 0.85-1.67) models. Compared with patients with fewer than 5 ambulatory visits for diabetes, patients with 5 or more outpatient visits in the preceding year were $36 \%$ more likely to have an ED visit for diabetes (aHR, 1.36; $95 \%$ CI, 1.11-1.66). In addition, the risk of diabetes-related ED visits was associated with a significant increase among patients who had a comorbidity such as CHF (aHR, 1.77; 95\% CI, 1.25-2.52) and CPD (aHR, 1.92; 95\% CI, 1.32-2.80).

After analyzing sex and controlling for other variables, we determined that men who were relapsed smokers had a significantly higher risk of diabetes-related ED visits compared with men who were nonsmokers (aHR, 2.05; 95\% CI, 1.13-3.71) (Table 3). We also observed that the adjusted risk for women who were continuing smokers was significantly higher than that for women who were nonsmokers (aHR, 1.65; 95\% CI, 1.10-2.47). Despite there being no significance for relapsed smokers compared with nonsmokers among the women, results showed an increased risk tendency of ED visits for diabetes when the adjusted model was used (aHR $=$ $1.20,95 \% \mathrm{CI}, 0.61-2.35)$.

\section{Discussion}

This study used the LSU HCSD data to examine the association between smoking and diabetes-related ED visits among patients aged 65 years or older with diabetes. The findings of this study revealed that $11.9 \%$ of older patients with diabetes are current smokers (including those who are continuing smokers or relapsed smokers). The current smoking rate in our study is slightly higher than that from the National Health Interview Survey (8.5\%) (25). This high smoking rate for older patients with diabetes might be attributable to certain characteristics of patients who seek care in LSU hospitals. LSU HCSD serves large groups of Louisiana's uninsured and low-income citizens (13). Low-income populations have higher rates of tobacco use (26). Additionally, a previous

\footnotetext{
The opinions expressed by authors contributing to this journal do not necessarily reflect the opinions of the U.S. Department of Health and Human Services, the Public Health Service, the Centers for Disease Control and Prevention, or the authors' affiliated institutions.
} 
study using this data set reported that the smoking rate was around $31 \%$, which is higher than the state's average (13). Our study demonstrates that older patients with diabetes who are relapsed smokers possess a significantly higher risk of diabetes-related ED visits than those who are nonsmokers. These findings are consistent with prior literature showing an association between smoking and increased ED use in populations with other chronic diseases, such as asthma (27). One study pointed out that patients with diabetes who are smokers had a higher average hemoglobin $\mathrm{A}_{1 \mathrm{c}}$ and higher insulin resistance than those who are nonsmokers (28), which supports our findings that older patients with diabetes who are smokers have an increased risk of diabetes-related ED visits. Therefore, we suggest that patients who are relapsed or continuing smokers should stop smoking to reduce the risk of ED use for diabetes.

Our data also suggest that older patients with diabetes who had had 5 or more outpatient visits for diabetes in a calendar year should be more diligent regarding follow-up care. These patients had a significant risk of increased diabetes-related ED visits compared with patients with fewer than 5 outpatient visits. In addition, older patients with diabetes with comorbidities of CHF or CPD should be especially mindful of diabetes management because of our finding of an increased risk of ED use in these populations. In terms of a stratified analysis by sex, the data suggest that a higher risk of diabetes-related ED visits is associated with men with diabetes who are relapsed smokers and women with diabetes who are continuing smokers. As a result, these patients may represent major target populations for smoking cessation interventions, which may significantly lower their risk of diabetes-related ED visits.

Our study demonstrates that smoking plays an important role in increasing the risk of diabetes-related ED visits among older patients with diabetes. These findings also suggest that smoking cessation is favorable for both patients and health care systems. Therefore, we recommend designing more efficient smoking cessation interventions for senior smokers with diabetes to increase their motivation to quit, thereby improving their rate of smoking cessation. These interventions include smoking cessation programs (29), diabetes management counseling and other forms of treatment as a component of diabetes care (12), and cessation advice from physicians (30).

This study has some limitations. First, the electronic health care record used by LSU HCSD is designed to remind physicians to ask their patients' smoking status every 90 days rather than at each outpatient visit. Therefore, we only included patients with more than 2 time points of recorded smoking status that were more than 90 days apart. Additionally, in this study we defined "nonsmokers" as never smokers and smokers who had already quit smoking for more than 1 year. This might have limited the gener- alizability for these patients. Second, the data did not include information on number of cigarettes consumed. Therefore, this study cannot identify patients' nicotine dependence. Third, we could not obtain patients' educational level or household income, which may have affected ED use. However, we considered insurance type, which might be associated with number of ED visits (5). Moreover, this study does not capture ED use and other health care use that did not occur in the LSU public hospital system. The results in this study may therefore underestimate patients' actual ED use. Lastly, the patient population that the hospital system predominantly serves could further affect the generalizability of the results.

Although some limitations exist, there are several strengths in this study. First, this study applied a longitudinal design to present stronger evidence of an association between smoking status and diabetes-related ED visits. Second, the large EHR databases used in this study reduce the effect of recall or self-report bias, thereby delivering results that are more valid than those from surveys (20). Third, we focused on the association between smoking status and diabetes-related ED visits and used criteria to identify patients' smoking status regarding their smoking behavior in the past 30 days and 1 year. These criteria were then used to more precisely reflect patients' actual smoking behavior and examine the association between smoking status and ED visits for diabetes. Finally, previous literature has only explored factors that are associated with quitting smoking after the diagnosis of diabetes. Our study provides empirical evidence of a higher risk of diabetes-related ED visits among older patients who are relapsed smokers.

Our study shows that older continuing and relapsed smokers with diabetes have a higher risk of diabetes-related ED visits than do younger continuing and relapsed smokers. From a primary care perspective, we recommend that primary care physicians provide more intensive diabetes management strategies for these patients to decrease disease progression. In addition, older smokers with diabetes should be encouraged to quit smoking to improve diabetes management.

\section{Acknowledgments}

This work was supported by a contract (CFMS no 599454) from the Louisiana Cancer Research Consortium through the Louisiana Campaign for Tobacco-Free Living and by the Postdoctoral Research Abroad Program (MOST 106-2917-I-564-039) from the Ministry of Science and Technology of the Republic of China (Taiwan).

The authors report no conflicts of interests.

The opinions expressed by authors contributing to this journal do not necessarily reflect the opinions of the U.S. Department of Health and Human Services, the Public Health Service, the Centers for Disease Control and Prevention, or the authors' affiliated institutions. 


\section{Author Information}

Corresponding Author: Tung-Sung Tseng, DrPH, Behavioral and Community Health Sciences, School of Public Health, Louisiana State University Health Sciences Center New Orleans, 2020 Gravier St, Room 213, New Orleans, LA 70112. Telephone: 504568-6022. Email: ttseng@1suhsc.edu.

Author Affiliations: ${ }^{1}$ Behavioral and Community Health Sciences, School of Public Health, Louisiana State University Health Sciences Center New Orleans, New Orleans, Louisiana. ${ }^{2}$ Health Care Services Division, Louisiana State University Health Sciences Center New Orleans, New Orleans, Louisiana. ${ }^{3}$ Biostatistics, School of Public Health, Louisiana State University Health Sciences Center New Orleans, New Orleans, Louisiana. ${ }^{4}$ Nafang Hospital of Southern Medical University, Guangzhou, Guangzhou, China.

\section{References}

1. Menke A, Casagrande S, Geiss L, Cowie CC. Prevalence of and trends in diabetes among adults in the United States, 1988-2012. JAMA 2015;314(10):1021-9.

2. Shim RS, Druss BG, Zhang S, Kim G, Oderinde A, Shoyinka $\mathrm{S}$, et al. Emergency department utilization among Medicaid beneficiaries with schizophrenia and diabetes: the consequences of increasing medical complexity. Schizophr Res 2014;152(2-3):490-7.

3. Centers for Disease Control and Prevention. National Diabetes Statistics Report, 2017. Atlanta (GA): Centers for Disease Control and Prevention, US Department of Health and Human Services; 2017. https://www.cdc.gov/diabetes/pdfs/data/ statistics/national-diabetes-statistics-report.pdf. Accessed October 3, 2018.

4. Gregg EW, Cheng YJ, Srinivasan M, Lin J, Geiss LS, Albright AL, et al. Trends in cause-specific mortality among adults with and without diagnosed diabetes in the USA: an epidemiological analysis of linked national survey and vital statistics data. Lancet 2018;391(10138):2430-40.

5. Washington RE, Andrews RM, Mutter RL. Emergency department visits for adults with diabetes, 2010. HCUP statistical brief \#167. Rockville (MD): Agency for Healthcare Research and Quality; 2013. http://www.hcup-us.ahrq.gov/ reports/statbriefs/sb167.pdf. Accessed October 25, 2018.

6. American Diabetes Association. Economic costs of diabetes in the U.S. in 2017. Diabetes Care 2018;41(5):917-28.
7. US Department of Health and Human Services. A report of the Surgeon General. How tobacco smoke causes disease: what it means to you. Atlanta (GA): US Department of Health and Human Services, Centers for Disease Control and Prevention, National Center for Chronic Disease Prevention and Health Promotion, Office on Smoking and Health; 2010. https:// www.cdc.gov/tobacco/data_statistics/sgr/2010/consumer_ booklet/pdfs/consumer.pdf. Accessed December 5, 2018.

8. Kar D, Gillies C, Zaccardi F, Webb D, Seidu S, Tesfaye S, et al. Relationship of cardiometabolic parameters in non-smokers, current smokers, and quitters in diabetes: a systematic review and meta-analysis. Cardiovasc Diabetol 2016;15(1):158.

9. Javed F, Al-Kheraif AA, Salazar-Lazo K, Yanez-Fontenla V, Aldosary KM, Alshehri M, et al. Periodontal inflammatory conditions among smokers and never-smokers with and without type 2 diabetes mellitus. J Periodontol 2015; 86(7):839-46.

10. Sherman JJ. The impact of smoking and quitting smoking on patients with diabetes. Diabetes Spectr 2005;18(4):202-8.

11. Lycett D, Nichols L, Ryan R, Farley A, Roalfe A, Mohammed MA, et al. The association between smoking cessation and glycaemic control in patients with type 2 diabetes: a THIN database cohort study. Lancet Diabetes Endocrinol 2015; 3(6):423-30.

12. American Diabetes Association. Standards of medical care in diabetes -2017 abridged for primary care providers. Clin Diabetes 2017;35(1):5-26.

13. Tseng TS, Moody-Thomas S, Horswell R, Yi Y, Celestin MD, Jones KD. Using a health informatics system to assess effect of a federal cigarette tax increase on readiness to quit among lowincome smokers, Louisiana, 2009. Prev Chronic Dis 2014; 11:E52.

14. Frieden TR, Bassett MT, Thorpe LE, Farley TA. Public health in New York City, 2002-2007: confronting epidemics of the modern era. Int J Epidemiol 2008;37(5):966-77.

15. Blumenthal D, Tavenner M. The "meaningful use" regulation for electronic health records. N Engl J Med 2010; 363(6):501-4.

16. Boyle R, Solberg L, Fiore M. Use of electronic health records to support smoking cessation. Cochrane Database Syst Rev 2014;(12):CD008743.

17. Moody-Thomas S, Celestin MD Jr, Tseng TS, Horswell R. Patient tobacco use, quit attempts, and perceptions of healthcare provider practices in a safety-net healthcare system. Ochsner J 2013;13(3):367-74.

18. Centers for Medicare and Medicaid Services. CCW chronic conditions algorithms. https:/www2.ccwdata.org/documents/ 10280/19139421/ccw-chronic-condition-algorithms.pdf. Accessed October 7, 2019.

\footnotetext{
The opinions expressed by authors contributing to this journal do not necessarily reflect the opinions of the U.S. Department of Health and Human Services, the Public Health Service, the Centers for Disease Control and Prevention, or the authors' affiliated institutions.
} 
19. Meyers JL, Parasuraman S, Bell KF, Graham JP, Candrilli SD. The high-cost, type 2 diabetes mellitus patient: an analysis of managed care administrative data. Arch Public Health 2014; 72(1):6.

20. Egede LE. Patterns and correlates of emergency department use by individuals with diabetes. Diabetes Care 2004; 27(7):1748-50.

21. Chiou SJ, Campbell C, Horswell R, Myers L, Culbertson R. Use of the emergency department for less-urgent care among type 2 diabetics under a disease management program. BMC Health Serv Res 2009;9(1):223.

22. Quan H, Sundararajan V, Halfon P, Fong A, Burnand B, Luthi $\mathrm{JC}$, et al. Coding algorithms for defining comorbidities in ICD9-CM and ICD-10 administrative data. Med Care 2005; 43(11):1130-9.

23. Smith PH, Kasza KA, Hyland A, Fong GT, Borland R, Brady $\mathrm{K}$, et al. Gender differences in medication use and cigarette smoking cessation: results from the International Tobacco Control Four Country Survey. Nicotine Tob Res 2015; 17(4):463-72.

24. Schoenfeld D. Partial residuals for the proportional hazards regression model. Biometrika 1982;69(1):239-41.

25. Jamal A, Homa DM, O’Connor E, Babb SD, Caraballo RS, Singh $\mathrm{T}$, et al. Current cigarette smoking among adults United States, 2005-2014. MMWR Morb Mortal Wkly Rep 2015;64(44):1233-40.

26. Jamal A, Phillips E, Gentzke AS, Homa DM, Babb SD, King BA, et al. Current cigarette smoking among adults - United States, 2016. MMWR Morb Mortal Wkly Rep 2018; 67(2):53-9.

27. Silverman RA, Hasegawa K, Egan DJ, Stiffler KA, Sullivan AF, Camargo CA Jr. Multicenter study of cigarette smoking among adults with asthma exacerbations in the emergency department, 2011-2012. Respir Med 2017;125:89-91.

28. Nilsson PM, Gudbjörnsdottir S, Eliasson B, Cederholm J; Steering Committee of the Swedish National Diabetes Register. Smoking is associated with increased $\mathrm{HbAlc}$ values and microalbuminuria in patients with diabetes - data from the National Diabetes Register in Sweden. Diabetes Metab 2004;30(3):261-8.

29. Mullen KA, Manuel DG, Hawken SJ, Pipe AL, Coyle D, Hobler LA, et al. Effectiveness of a hospital-initiated smoking cessation programme: 2-year health and healthcare outcomes. Tob Control 2017;26(3):293-9.

30. Winpenny E, Elliott MN, Haas A, Haviland AM, Orr N, Shadel WG, et al. Advice to quit smoking and ratings of health care among Medicare beneficiaries aged 65. Health Serv Res 2017;52(1):207-19.

The opinions expressed by authors contributing to this journal do not necessarily reflect the opinions of the U.S. Department of Health and Human Services, the Public Health Service, the Centers for Disease Control and Prevention, or the authors' affiliated institutions. 


\section{Tables}

Table 1. Characteristics of Study Population $(\mathrm{N}=2,114)$ by Smoking Status, Louisiana State University Health Care Services Division, 2009-2011 ${ }^{\text {a }}$

\begin{tabular}{|c|c|c|c|c|c|c|}
\hline Variables & Overall & Nonsmoker & Former Smoker & Continuing Smoker & Relapsed Smoker & $P$ Value $^{\mathrm{b}}$ \\
\hline Overall & $2,114(100.0)$ & 1,777 (84.1) & $86(4.1)$ & $174(8.2)$ & 77 (3.6) & $<.001$ \\
\hline Age, mean (SD), y & $71.0(5.6)$ & $71.4(5.8)$ & $70.4(5.4)$ & $68.8(4.0)$ & $68.7(3.5)$ & $<.001^{\mathrm{C}}$ \\
\hline \multicolumn{7}{|l|}{ Sex } \\
\hline Female & $1,358(64.2)$ & $1,168(65.7)$ & $48(55.8)$ & $99(56.9)$ & $43(55.8)$ & \multirow{2}{*}{.01} \\
\hline Male & $756(35.8)$ & 609 (34.3) & $38(44.2)$ & 75 (43.1) & $34(44.2)$ & \\
\hline \multicolumn{7}{|l|}{ Race } \\
\hline African American & $1,022(48.3)$ & $856(48.2)$ & $51(59.3)$ & 75 (43.1) & $40(52.0)$ & \multirow{3}{*}{.18} \\
\hline White & $1,026(48.5)$ & $864(48.6)$ & $33(38.4)$ & $92(52.9)$ & $37(48.1)$ & \\
\hline Other & $66(3.1)$ & $57(3.2)$ & $2(2.3)$ & $7(4.0)$ & 0 & \\
\hline \multicolumn{7}{|l|}{ Insurance type } \\
\hline Commercial & 336 (15.9) & $278(15.6)$ & $14(16.3)$ & $34(19.5)$ & $10(13.0)$ & \multirow{5}{*}{.14} \\
\hline Free care & $163(7.7)$ & $135(7.6)$ & $5(5.8)$ & $16(9.2)$ & $7(9.1)$ & \\
\hline Medicaid & $28(1.3)$ & $21(1.2)$ & $1(1.2)$ & $6(3.5)$ & 0 & \\
\hline Medicare & 1,563 (73.9) & $1,323(74.5)$ & $63(73.3)$ & $117(67.2)$ & $60(77.9)$ & \\
\hline Self-pay & $24(1.1)$ & $20(1.1)$ & $3(3.5)$ & $1(0.6)$ & 0 & \\
\hline \multicolumn{7}{|c|}{ Type 2 diabetes mellitus outpatient visits } \\
\hline $0-4$ & $1,420(67.2)$ & $1,202(67.6)$ & $51(59.3)$ & $115(66.1)$ & $52(67.5)$ & \multirow{2}{*}{.44} \\
\hline$\geq 5$ & $694(32.8)$ & $575(32.4)$ & $35(40.7)$ & 59 (33.9) & $25(32.5)$ & \\
\hline \multicolumn{7}{|c|}{ Type 2 diabetes mellitus inpatient visits } \\
\hline 0 & $2,104(99.5)$ & $1,768(99.5)$ & $86(100.0)$ & $173(99.4)$ & $77(100.0)$ & \multirow{2}{*}{$.82^{\mathrm{d}}$} \\
\hline$\geq 1$ & $10(0.5)$ & $9(0.5)$ & $0(0.0)$ & $1(0.6)$ & 0 & \\
\hline \multicolumn{7}{|c|}{ Charlson Comorbidity Index } \\
\hline 0 & $1,402(66.3)$ & $1,184(66.6)$ & $56(65.1)$ & $116(66.7)$ & $46(59.7)$ & \multirow{3}{*}{.11} \\
\hline 1 & $255(12.1)$ & $202(11.4)$ & $11(12.8)$ & $31(17.8)$ & $11(14.3)$ & \\
\hline$\geq 2$ & $457(21.6)$ & $391(22.0)$ & $19(22.1)$ & $27(15.5)$ & $20(26.0)$ & \\
\hline \multicolumn{7}{|c|}{ Congestive heart failure } \\
\hline No & $1,934(91.5)$ & $1,619(91.1)$ & $81(94.2)$ & $163(93.7)$ & $71(92.2)$ & \multirow{2}{*}{.52} \\
\hline Yes & $180(8.5)$ & $158(8.9)$ & $5(5.8)$ & $11(6.3)$ & $6(7.8)$ & \\
\hline \multicolumn{7}{|c|}{ Peripheral vascular disease } \\
\hline No & $2,061(97.5)$ & $1,736(97.7)$ & $85(98.8)$ & $166(95.4)$ & $74(96.1)$ & \multirow{2}{*}{$.18^{\mathrm{d}}$} \\
\hline Yes & $53(2.5)$ & $41(2.3)$ & $1(1.2)$ & $8(4.6)$ & $3(3.9)$ & \\
\hline
\end{tabular}

${ }^{a}$ All data are number (percentage) unless otherwise indicated.

${ }^{b} x^{2}$ test unless otherwise indicated.

${ }^{\mathrm{c}}$ Analysis of variance.

${ }^{\mathrm{d}}$ Fisher exact test.

${ }^{\mathrm{e}}$ Reference 21. 
(continued)

Table 1. Characteristics of Study Population $(\mathrm{N}=2,114)$ by Smoking Status, Louisiana State University Health Care Services Division, 2009-2011 ${ }^{\mathrm{a}}$

\begin{tabular}{|c|c|c|c|c|c|c|}
\hline Variables & Overall & Nonsmoker & Former Smoker & Continuing Smoker & Relapsed Smoker & $P$ Value $^{\mathrm{b}}$ \\
\hline \multicolumn{7}{|c|}{ Cerebrovascular disease } \\
\hline No & $2,075(98.2)$ & $1,751(98.5)$ & $83(96.5)$ & $168(96.6)$ & $73(94.8)$ & \multirow{2}{*}{$.012^{\mathrm{d}}$} \\
\hline Yes & $39(1.8)$ & $26(1.5)$ & $3(3.5)$ & $6(3.5)$ & $4(5.2)$ & \\
\hline \multicolumn{7}{|c|}{ Chronic pulmonary disease } \\
\hline No & $1,972(93.3)$ & $1,670(94.0)$ & $78(90.7)$ & $154(88.5)$ & $70(90.9)$ & \multirow{2}{*}{.02} \\
\hline Yes & $142(6.7)$ & $107(6.0)$ & $8(9.3)$ & $20(11.5)$ & 7 (9.1) & \\
\hline \multicolumn{7}{|c|}{ Emergency department visit for type 2 diabetes mellitus } \\
\hline No & $1,700(80.4)$ & $1,439(81.0)$ & $71(82.6)$ & $135(77.6)$ & $55(71.4)$ & \multirow{2}{*}{.14} \\
\hline Yes & $414(19.6)$ & $338(19.0)$ & $15(17.4)$ & $39(22.4)$ & $22(28.6)$ & \\
\hline
\end{tabular}

${ }^{a}$ All data are number (percentage) unless otherwise indicated.

${ }^{b} x^{2}$ test unless otherwise indicated.

${ }^{c}$ Analysis of variance.

${ }^{\mathrm{d}}$ Fisher exact test.

${ }^{\mathrm{e}}$ Reference 21. 
Table 2. Factors Associated With Emergency Department Use for Type 2 Diabetes Mellitus Using Cox Models ( $\mathrm{N}=2,114)$, Louisiana State University Health Care Services Division, 2009-2011

\begin{tabular}{|c|c|c|}
\hline Factor & Crude Hazard Ratio (95\% Confidence Interval) & Adjusted Hazard Ratio ( $95 \%$ Confidence Interval) \\
\hline \multicolumn{3}{|c|}{ Smoking status (reference: nonsmoker) } \\
\hline Former smoker & $0.94(0.56-1.58)$ & $0.91(0.54-1.52)$ \\
\hline Continuing smoker & $1.19(0.85-1.65)$ & $1.19(0.85-1.67)$ \\
\hline Relapsed smoker & $1.56(1.01-2.40)$ & $1.62(1.04-2.50)$ \\
\hline Age & $1.01(1.00-1.03)$ & $1.01(1.00-1.03)$ \\
\hline \multicolumn{3}{|c|}{ Sex (reference: male) } \\
\hline Female & $0.98(0.80-1.19)$ & $1.00(0.81-1.22)$ \\
\hline \multicolumn{3}{|c|}{ Race (reference: white) } \\
\hline African American & $1.00(0.82-1.22)$ & $1.06(0.87-1.30)$ \\
\hline Other & $1.09(0.63-1.87)$ & $1.27(0.73-2.20)$ \\
\hline \multicolumn{3}{|c|}{ Insurance type (reference: commercial) } \\
\hline Free care & $0.87(0.54-1.40)$ & $0.91(0.56-1.48)$ \\
\hline Medicaid & $1.26(0.54-2.93)$ & $1.34(0.57-3.16)$ \\
\hline Medicare & $1.29(0.97-1.72)$ & $1.25(0.94-1.67)$ \\
\hline Self-pay & $0.98(0.35-2.70)$ & $1.12(0.41-3.10)$ \\
\hline \multicolumn{3}{|c|}{ Type 2 diabetes mellitus outpatient visits (reference: $0-4$ ) } \\
\hline$\geq 5$ & $1.33(1.10-1.63)$ & $1.36(1.11-1.66)$ \\
\hline \multicolumn{3}{|c|}{ Type 2 diabetes mellitus inpatient visits (reference: 0 ) } \\
\hline$\geq 1$ & $1.82(0.59-5.67)$ & $2.41(0.77-7.60)$ \\
\hline \multicolumn{3}{|c|}{ Charlson Comorbidity Index ${ }^{a}$ (reference: 0 ) } \\
\hline 1 & $1.41(1.08-1.86)$ & $0.90(0.62-1.31)$ \\
\hline$\geq 2$ & $1.01(0.79-1.29)$ & $0.79(0.59-1.05)$ \\
\hline \multicolumn{3}{|c|}{ Congestive heart failure (reference: no) } \\
\hline Yes & $1.65(1.24-2.21)$ & $1.77(1.25-2.52)$ \\
\hline \multicolumn{3}{|c|}{ Peripheral vascular disease (reference: no) } \\
\hline Yes & $0.65(0.31-1.38)$ & $0.66(0.30-1.42)$ \\
\hline \multicolumn{3}{|c|}{ Cerebrovascular disease (reference: no) } \\
\hline Yes & $1.19(0.62-2.31)$ & $1.34(0.66-2.73)$ \\
\hline \multicolumn{3}{|c|}{ Chronic pulmonary disease (reference: no) } \\
\hline Yes & $1.82(1.34-2.48)$ & $1.92(1.32-2.80)$ \\
\hline
\end{tabular}

${ }^{\mathrm{a}}$ Reference 21.

The opinions expressed by authors contributing to this journal do not necessarily reflect the opinions of the U.S. Department of Health and Human Services, the Public Health Service, the Centers for Disease Control and Prevention, or the authors' affiliated institutions. 
Table 3. Stratification by Sex to Compare the Risk of Emergency Department Use for Type 2 Diabetes Mellitus Across Smoking Status in Cox Models

\begin{tabular}{|c|c|c|c|c|}
\hline \multirow[b]{2}{*}{ Smoking status } & \multicolumn{2}{|c|}{ Women } & \multicolumn{2}{|c|}{ Men } \\
\hline & $\begin{array}{l}\text { Crude Hazard Ratio (95\% } \\
\text { Confidence Interval) }\end{array}$ & $\begin{array}{c}\text { Adjusted Hazard Ratio (95\% } \\
\text { Confidence Interval) }\end{array}$ & $\begin{array}{l}\text { Crude Hazard Ratio (95\% } \\
\text { Confidence Interval) }\end{array}$ & $\begin{array}{l}\text { Adjusted Hazard Ratio }{ }^{a} \text { (95\% } \\
\text { Confidence Interval) }\end{array}$ \\
\hline Former vs nonsmoker & $1.35(0.74-2.48)$ & $1.27(0.69-2.35)$ & $0.50(0.18-1.35)$ & $0.47(0.17-1.29)$ \\
\hline $\begin{array}{l}\text { Continuing vs } \\
\text { nonsmoker }\end{array}$ & $1.68(1.14-2.47)$ & $1.65(1.10-2.47)$ & $0.63(0.33-1.19)$ & $0.67(0.35-1.29)$ \\
\hline $\begin{array}{l}\text { Relapsed vs } \\
\text { nonsmoker }\end{array}$ & $1.14(0.59-2.22)$ & $1.20(0.61-2.35)$ & $2.04(1.15-3.62)$ & $2.05(1.13-3.71)$ \\
\hline
\end{tabular}

${ }^{a}$ Adjusted for age, race, insurance type, type 2 diabetes mellitus outpatient visits, diabetes mellitus inpatient visits, Charlson comorbidity index (21), congestive heart failure, peripheral vascular disease, cerebrovascular disease, and chronic pulmonary disease. 